\title{
The effect of amblyopia on educational activities of students aged 9 - 15
}

\author{
M. Khalaj ${ }^{1}$, I. Mohammadi Zeidi ${ }^{1}$, M. R. Gasemi ${ }^{1}$, Ahmad Keshtkar ${ }^{2}$
}

${ }^{1}$ School of Public Health, Qazvin University of Medical Sciences, Bahonar Blvd, Qazvin, Iran;
${ }^{2}$ Medical Faculty, Medical Physics Department, Tabriz University of Medical Sciences, Tabriz, Iran.
Email: mpp98ak@hotmail.com

Received 12 April 2011; revised 24 May 2011; accepted 10 June 2011.

\begin{abstract}
Amblyopia is an illness with reduced vision and a number of students are affected with this disease. To determine any association of amblyopia with educational activities, sport and social activities of students involved by amblyopia, this study was carried on. This study was conducted at Boali Hospital in Gazvin, Iran: A total of 110 patients 9 to 15 years $(54.5 \%$ female and $45.5 \%$ male; mean age: $13.7 \pm 3.2$ ) with amblyopia (20/25 - 20/400) due to strabismus and/or refractive errors, and that persisted after treatment with spectacles. All children wore eyeglasses containing their refractive correction (based on cycloplegic autorefractor measurements, refined or confirmed by cycloplegic retinoscopy or subjective refinement) for acuity testing. The results indicated that, $25(22.73 \%)$ patients with strabismus amblyopia, 40 (36.36\%) patients anisometropic amblyopia, $22(20 \%)$ patients ametropic amblyopia, $18(16.36 \%)$ patients with strabismic mixed with anisometropia and 5 (4.55) with deprived amblyopia. Parent's knowledge about meaning of amblyopia and amblyopia-related phenomena in $50(45.5 \%)$ of patiens was very low. The educational level in $45(41 \%)$ of parents were reported to be primary school, $40(36.3 \%)$ higher school and university degrees $25(22.7 \%)$. The sport activity in 35 (31.8\%) of patients with amblyopia was very low and in $14(12.7 \%)$ higher than others. In a comparison with other students, the educational qualification in $18(16.4 \%)$ was very low, $35(32 \%)$ the as equal as others and $27(24.5 \%)$ higher than their classmate. Visual acuity with the best correction, in $75(67 \%)$ of patients was $20 / 25$, in $30(27.27 \%)$ patients $20 / 40$ or worse and in $5(4.5 \%)$ of them $20 / 200$ or worse. Poor eyesight and amblyopia can influence on learning, sport and social activity, and performance in school, as well as restrict choice in profession and hobbies. The parent's knowledge of amblyopia is high efficiency of treatment of the amblyopia patient's morale.
\end{abstract}

Keywords: Amblyopia-Visual; Acuity-Anisometropia Strabismus

\section{INTRODUCTION}

Amblyopia, or lazy eye, defined as a reduction in corrected visual acuity (VA) in the absence of visible organic abnormalities. This is the most common cause of visual impairment in both children and middle-aged adults, affects approximately $1.5 \%$ to $3 \%$ of the population. This carries a projected lifetime risk of visual loss of at least $1.2 \%$ [1-5]. Amblyopia is clinically defined as a two lines or greater difference in visual acuity (VA) between the eyes in the presence of a predisposing amblyogenic condition, and in the absence of visible ocular or visual pathway disease [6]. It is occurs because child's visual system does not develop properly, resulting in abnormal sight in one or both eyes [7]. Amblyopia can be treated effectively in young children, if left uncorrected, this vision problem can lead to abnormal neurodevelopment of the visual system and then visual loss may be permanent [8-10]. Many eye care professionals believe that treatment beyond early of life age of 6 or 7 years, is ineffective and a treatment response is unlikely, while others consider age 9 or 10 years to be the upper age limit for successful treatment [11-14]. The American Academy of Ophthalmology Preferred Practice Pattern for amblyopia recommends treatment up to age 10 years [15]. Amblyopia, when diagnosed in children, is usually treated with occlusion (patching) of the sound eye or therapy with a cycloplegic drug (atropine) that dilates the pupils and blurs the image seen by eye, has been known for almost a century. Occlusion therapy is subject to problems of compliance, due to the child's dislike of wearing a patch for visual, skin irritation, and social/psychological reasons [16]. Therefore the penalization methods are effective methods for the treatment of amblyopia, with a low risk of occlusion amblyopia. 
Patient acceptance of these methods was good [17]. The most common causes of amblyopia is a congenital or early acquired cataract, but corneal opacities, vitreous hemorrhage, and ptosis also may be implicated. Deprivation of the form of vision is the least common form of amblyopia but most damaging and difficult to treat. Amblyopic visual loss resulting from a unilateral occlusion of the visual axis tends to be worse than that produced by bilateral deprivation of similar degree because interocular effects add to the direct developmental impact of severe image degradation. Even in bilateral cases, however, visual acuity can be 20/200 or worse. Unilateral cataracts have a better prognosis when the cataract is removed and optical correction is in place by 3 months of age to minimize deprivation and maximize visual prognosis $[18,19]$. Most of the available data on the natural history of amblyopia and success rates of its treatment with either patching or drug therapy are retrospective and uncontrolled. Despite the common occurrence of amblyopia, there is little quality data on treatment of this condition. Thus, there is much to be learned about the course of treated amblyopia, to provide more precise estimates of success rates and to identify factors that may be associated with successful and unsuccessful treatment. A recent population-based study of educational, health, and social outcomes, which failed to identify any "real-life" functional impact of the visual deficits associated with amblyopia, highlighted the need for further research on what it means to have amblyopia [20]. We report an investigation of the association of amblyopia with diverse health and social outcomes. In the present investigation, we provides an opportunity to determine the affects the educational, sport and social activities of amblyopia patients aged 9 to 15 years old in Qazvin city in Iran.

\section{METHODS}

The study was performed at Buali eye clinical in Qazvin-Iran. A total of one hundred ten children participated in the study, including 60 female (54/5\%) and 40 male (45/5\%) aged 9 to 15 years, mean age: $13.7 \pm 3.2$ [SD]. Subjects were enrolled between January 2007 and April 2008 in a randomized trial had best-corrected visual acuity (VA) of 20/25 to 20/400 with amblyopia resulting from strabismus, anisometropia or both, and refractive errors. Children (9, 10, 11, 12, 13, 14 and 15 years) were invited to attend in a research clinic. Patients had to have refractive error in each eye between \pm 0.5 and \pm 9.00 diopters (D). For doing some eye examination parents of all subjects and their teachers were contacted by letter and telephone to invite them to participate and 95\% of them agreed to participate [21]. Parents completed a comprehensive 30-item questionnaire that addressed basic sociodemographic factors such as ethnicity, parental edu- cation, occupation and social activities of student. Cycloplegic autorefraction was performed with an autorefractor (model RK-F1; Canon, Tokyo, Japan). This instrument generated three reliable readings of refraction in each eye; the median reading was used for analysis. Cycloplegia was induced using cyclopentolate 1\% (1 drop), 2 minutes after corneal anesthesia with amethocaine $0.5 \%$. Tropicamide 1\% (1 drop) and phenylephrine 2.5\% (1 drop) were also used in some children to obtain adequate mydriasis (a minimum pupil diameter of $6 \mathrm{~mm}$ ). Autorefraction was repeated 30 minutes after the last drop [22].

Measurement of ocular biometric parameters was performed with an optical biometer. By using Snellen charts, at distance of 6 meter (20 feet), visual acuity in each eye and an examination for strabismus by trained medical examiners was measured [23]. The child read the first letter of each row from the top of the logMAR chart until an error was made (screening). The child was then redirected to two rows above the screening error row and asked to attempt each letter until four incorrect responses were given [24]. All children wore eyeglasses containing their refractive correction (based on cycloplegic autorefractor measurements, refined or confirmed by cycloplegic retinoscopy or subjective refinement) for acuity testing. We invited all children to a vision assessment at all years, including measurement of visual acuity both with and without a pinhole (with pinhole as a proxy for correction by spectacles). We sent out a questionnaire on family history and previous treatment with patching beforehand [25]. For this analysis, we excluded people with bilateral visual loss, unilateral loss inconsistent with amblyopia, or known eye diseases (such as cataract), as well as those whose vision was tested with and without their prescribed optical correction. Results were analyzed using SPSS program, to assess for factors that directly or indirectly influenced the amblyopia and evaluation social activities and other factors of amblyopic students compared to normal students.

\section{RESULTS}

Reading testing was completed by 110 students at 9 to 15 years, who were eligible, of whom 60 (54/5\%) female and 50 (45/5\%) were male; mean age, $13.7 \pm 3.2$. Of all, 75 (67\%) patients with the best correction had mild amblyopia (VA worse than 20/25), 30 (27.27\%) patients had moderate (VA worse than 20/40) and 5 (4.5\%) severe amblyopia (legal blindness, 20/200 or worse), Figure 1. Amblyopia was defined as best-corrected visual acuity of $20 / 25$ or worse in the absence of any pathological cause. Ninety-five (86.4\%) wore spectacles alone, 15 (13.6\%) were wore a combination of spectacles and contact lens. The prevalence of unilateral amblyopia was (50.5\%) and monolateral was (49.5\%). As shown in Table 1, Aniso- 
metropia was statistically more common in amblyopic cases (36.36\%) compared with (22.73\%) of strabismics, Anisometropia \& strabismic amblyopia (16.36\%), ametropic amblyopia (20\%), and patients with deprived amblyopia $(4.55 \%) \quad(\mathrm{p}<0.001)$. Parents knowledge about meaning of amblyopia and amblyopiarelated phenomena in 50 (45.5\%) of patiens was very low, 27 (24.5\%) middle and 33 (30\%) high. The literacy level in $45(41 \%)$ of parents, was about primary school in 40 (36.3\%), in high school and $25(22 / 7 \%)$ of them in university degree qualifications (Figure 2). The sport activity in 35 (31.8\%) of patients with amblyopia was very low, in 38 (34.5\%) low, in 23 (20.9\%) the same level as other students and in $14(12.7 \%)$ of students was higher than others. In a comparison with other students, the educational quailfication attained by 18 (16.4\%) was very low, in 30 (28\%) of students low, in 35 (32\%) was found to be the same level as other students and 27 (24.5\%) of them, had higher educational qualification than their classmate. As Shown in Table 2, the participation in social activities (going park, or to the cinema, meeting friends and families) in 60 (54.5\%) of amblyopic patients was very low, in 27 (28\%) low, $12(10.9 \%)$ was the same level as other students and $11(10 \%)$ of them, higher than their classmate. Amblyopia was found to be statistically different by gender $(p=0.01)$, in all age groups, the females were more activities than male.

\section{DISCUSSION}

It is generally agreed that amblyopia must be diagnosed and treated at an early age to prevent the loss of vision and that treatment is more extended and less effective in older nitudes of anisometropia had higher prevalence and greater depth of amblyopia [26]. Conduction of preventive programs directed to children requires the participation of

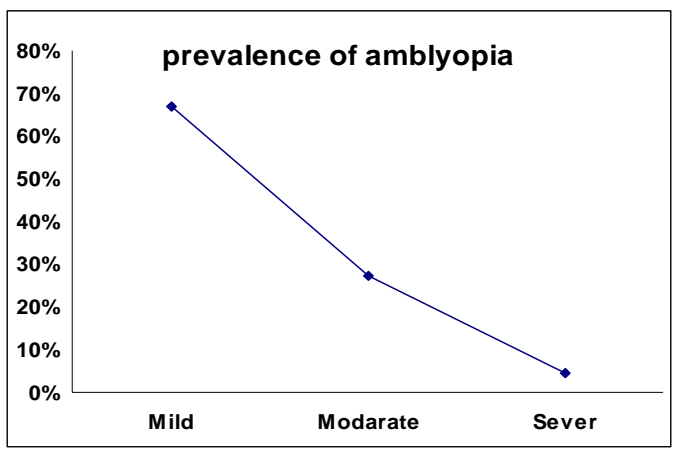

Figure 1. The means prevalence of mild, moderate and severe amblyopia in children aged 9 to 15 .

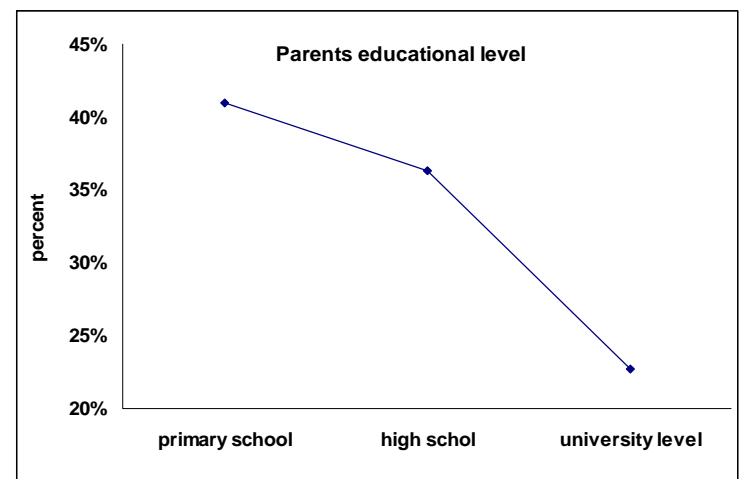

Figure 2. Parents literacy level of students with amblyopia in one or two eyes. About $41 \%$ of parents had a low level of education

ages. This study showed that children with higher mag-

Table 1. Prevalence of Amblyopia in Qazvin-Iran Children by Age (years).

\begin{tabular}{|c|c|c|c|c|c|c|c|c|c|c|c|}
\hline \multirow[t]{2}{*}{ Age } & \multicolumn{2}{|c|}{$\begin{array}{l}\text { Anisometropic } \\
\text { Amblyopia } \\
\text { [Prevalence (n)] }\end{array}$} & \multirow{2}{*}{\multicolumn{2}{|c|}{$\begin{array}{l}\text { Strabismic amblyopia } \\
\text { prevalence(N) } \\
\text { (N) } \quad(\%)\end{array}$}} & \multirow{2}{*}{\multicolumn{2}{|c|}{$\begin{array}{l}\text { Strabism\&aniso } \\
\text { amblyopia } \\
\text { lence(N) } \\
\text { (N) } \quad(\%)\end{array}$}} & \multicolumn{2}{|c|}{$\begin{array}{l}\text { Ametropia } \\
\text { amblyopia } \\
\text { prevalence (N) }\end{array}$} & \multicolumn{2}{|c|}{$\begin{array}{l}\text { Deprived am- } \\
\text { blyopia preva- } \\
\text { lence(N) }\end{array}$} & \multirow[t]{2}{*}{$\begin{array}{l}\text { Total } \\
\text { (N) (\%) }\end{array}$} \\
\hline & (N) & (\%) & & & & & (N) & $(\%)$ & (N) & (\%) & \\
\hline $9-10$ & 9 & $(42.86)$ & 6 & (28.57) & 2 & (9.52) & 3 & $(14.29)$ & 1 & $(4.76)$ & $21 \quad$ (19) \\
\hline $10-11$ & 8 & (44.44) & 2 & (11.11) & 2 & (11.11) & 5 & (27.8) & 1 & (5.5) & 18 (16.36) \\
\hline $11-12$ & 6 & (35.29) & 5 & (29.41) & 2 & (11.8) & 4 & (23.53) & & & 17 (15.45) \\
\hline $12-13$ & 8 & $(20)$ & 6 & $(30)$ & 2 & $(10)$ & 2 & $(10)$ & 2 & (10) & 20 (18.18) \\
\hline $13-14$ & 4 & (22.20) & 3 & (16.66) & 6 & (33.33) & 5 & (27.8) & & & 18 (16.36) \\
\hline $14-15$ & 5 & (31.25) & 3 & (18.75) & 4 & (25) & 3 & (18.75) & 1 & (6.25) & $16(14.55)$ \\
\hline Total & 40 & (36.36) & 25 & (22.73) & 18 & (16.36) & 22 & (20) & 5 & $(4.55)$ & $110(100)$ \\
\hline
\end{tabular}

Table 2. Below table shows the participation of students with amblyopia in social activities. About $54.5 \%$ of students had very low social activities in comparison with normal student.

\begin{tabular}{|c|c|c|c|c|c|c|c|}
\hline \multicolumn{8}{|c|}{ The participate of amblyopic students in social activities } \\
\hline \multicolumn{2}{|c|}{ Very low } & \multicolumn{2}{|c|}{ low } & \multicolumn{2}{|c|}{ Equal } & \multicolumn{2}{|l|}{ higher } \\
\hline$(\mathrm{N})$ & $(\%)$ & $(\mathrm{N})$ & $(\%)$ & $(\mathrm{N})$ & $(\%)$ & $(\mathrm{N})$ & (\%) \\
\hline (60) & $(54.5)$ & (27) & (28) & (12) & $(10.9)$ & (11) & (10) \\
\hline
\end{tabular}


several sectors of the community involving physicians, educators, parents and volunteer personnel. This study indicate that, on average, students with amblyopia can not expect to do as well as their peers with normal vision in both eyes in terms of educational attainment, sport, and social activities. We found that several factors can effect the improvement and or prevention of amblyopia (e.g. the role of parents, childhood socioeconomic environment etc.).

To our knowledge, no previous reports have addressed the importance of parents' educational level prospects for children with amblyopia. The parents' knowledge of amblyopia had an important role in educational attainment, employment, social achievement and etc and can encourage children attendance seriously in sports and educational environments and social activity. Amblyopic children who their parents familiar with amblyopia, do not seem to be disadvantaged in relation to social activities, nor are they at increased risk of behavioral difficulties or social maladjustment as children [20]. This study showed the knowledge of amblyopia in $45.5 \%$ of parent was very low and literacy level in $36.3 \%$ was about primary school. These factors can be involved in future activities in children with amblyopia in one or two eyes. Our results are different with Rahi and colleagues, which showed that, distinguishing, at a population level, between the lives of people with amblyopia and those without in terms of important educational, health, and social outcomes may be difficult. They cited that children with amblyopia did as well as those with normal vision on educational tests and was not associated with highest educational qualification achieved [20]. They reported that people with amblyopia were no more likely than those with normal vision to report poor general health, depression, or psychological distress in adulthood. Our study indicated that only 24.5\% of students was associated with highest educational qualification related to others, in contrast 18 (16.4\%) of student with amblyopic eyes was very low, in 30 (28\%) of them low, in 35 (32\%) was found to be the same level as other students, these may be as a result of parents knowledge of amblyopia and low educational level. Recent study in the UK showed that the lifetime risk to people with amblyopia of visual impairment or blindness through disease or injury to their normal eye is between $1 \%$ and $3 \%$ [27]. It is reported that amblyopia has been found to significantly reduce speed and dexterity of prehension (particularly in children with a history of strabismus), without diminishing accuracy and control [28-30]. Evidence also has come to light that amblyopic subjects' binocular reading speed is significantly slower than that of normal subjects, despite the amblyopic subjects having the same levels of binocular visual acuity and reading acuity as the normal subjects [31]. Woodruff and colloquies reported, pure anisometropic amblyopia had the best initial visual acuity, with $25 \%$ of anisometropes having an initial visual acuity of less than 6/18 compared with $39 \%$ of strabismics and $50 \%$ of mixed amblyopes [32]. Whereas our study showed that the prevalence of anisometropia was statistically more common in amblyopic cases (36.36\%) compared with $(22.73 \%)$ of strabismics, (16.36\%) of mixed amblyopes, (20\%) ametropic amblyopia. Our findings suggest a significant effect of amblyopia on the sports activities. Fewer children in the amblyopic Group in Qazvin had participated in higher sport activities (12.7\%).

This may be because the student with amblyopia had almost several times the risk of visual impairment in their better seeing eye with the best correction to less than 20/25 compared to students without amblyopia. This underlines the importance of continued childhood screening in the early of life and treatment of children with amblyopia in order to prevent or reduce the risk of visual impairment and have no significant behavioral problems, the well reported burden of disease associated with vision loss later in life. Chua and Mitchel found a borderline significant effect of amblyopia on higher university degrees but no effect on lifetime occupational class [33] Snowdon and Stewart-Brown interviewed health care professionals, adults with amblyopia, and children in amblyopia treatment to gain an understanding of how amblyopia and treatment for amblyopia affect people's lives [34]. Further longitudinal data are warranted to provide a more complete account of the natural history of amblyopia and the plasticity of the visual system [33]. Associations between performance at school and amblyopia are complicated by the independent associations of strabismus and refractive error with a variety of neurodevelopmental disorders, including those caused by premature birth. Nevertheless, bilateral visual deficits (which were excluded from Rahi and colleagues' study) that cannot be corrected with glasses are clearly associated with educational difficulty and reduced life chances [35].

\section{CONCLUSIONS}

It may be difficult to distinguish, at population level, between the lives of student with amblyopia and those without, in terms of several important outcomes. Our findings indicate that, on average, children with amblyopia can expect to do social activities but not as well as their peers with normal vision in both eyes in terms of educational attainment, employment, sport activities and socioeconomic achievement. But in some student with amblyopia do not seem to be disadvantaged in relation to social activities, nor are they at increased risk of behavioral difficulties or social maladjustment as children. 


\section{REFERENCES}

[1] Friendly, D.S. (1987) Amblyopia: Definition, classification, diagnosis, and management considerations for pediatricians, family physicians, and general practitioners. Pediatric Clinics of North America, 34, 1389-1401.

[2] Simons, K. (1996) Preschool vision screening: Rationale, methodology and outcome. Survey of Ophthalmology, 41, 3-30. doi:10.1016/S0039-6257(97)81990-X

[3] Simons, K. and Preslan, M. (1999) Natural history of amblyopia untreated owing to lack of compliance. British Journal of Ophthalmology, 83, 582-587. doi:10.1136/bjo.83.5.582

[4] Attebo, K., Mitchell, P., Cumming, R., Smith, W., Jolly, N. and Sparkes, R. (1998) Prevalence and causes of amblyopia in an adult population. Ophthalmology, 105, 154159. doi:10.1016/S0161-6420(98)91862-0

[5] Webber, A.L. and Wood, J. (2005) Amblyopia: Prevalence, natural history, functional effects and treatment. Clinical and Experimental Optometry, 88, 365-75. doi:10.1111/j.1444-0938.2005.tb05102.x

[6] Repka, M.X., Kraker, R.T., Tamkins, S.M., et al. (March 2009) Retinal nerve fiber layer thickness in amblyopic eyes. American Journal of Ophthalmology, 148, 143-147. doi:10.1016/j.ajo.2009.01.015

[7] Brown, S.A., Weih, L.M., Fu, C.L., Dimitrov, P., Taylor, H.R. and McCarty, C.A. (2000) Prevalence of amblyopia and associated refractive errors in an adult population in Victoria, Australia. Ophthalmic Epidemiol, 7, 249-258.

[8] Pediatric Eye Disease Investigator Group. (2002) A randomized trial of atropine vs patching for treatment of moderate amblyopia in children. Archives of Ophthalmology, 120, 268-278.

[9] Neumann, E., Friedman, Z. and Abel-Peleg, B. (1987) Prevention of strabismic amblyopia of early onset with special reference to the optimal age for screening. Journal of Pediatric Ophthalmology \& Strabismus, 24, 106-110.

[10] Daw, N.W. (1998) Critical periods and amblyopia. Archives of Ophthalmology, 116, 502-505.

[11] Scott, W.E. and Dickey, C.F. (1988) Stability of visual acuity in amblyopic patients after visual maturity. Graefe's Archive of Clinical and Experimental Ophthalmology, 226, 154-157. doi:10.1007/BF02173306

[12] Quah, B.L., Tay, M.T., Chew, S.J. and Lee, L.K. (1991) A study of amblyopia in 18 - 19 year old males. Singapore Medical Journal, 32, 126-129.

[13] Epelbaum, M., Milleret, C., Buisseret, P. and Dufier, J.L. (1993) The sensitive period for strabismic amblyopia in humans. Ophthalmology, 100, 323-327.

[14] Flynn, J.T., Schiffman, J., Feuer, W. and Corona, A. (1998) The therapy of amblyopia: An analysis of the results of amblyopia therapy utilizing the pooled data of published studies. Transactions of the American Ophthalmological Society, 96, 431-453.

[15] American Academy of Ophthalmology (2002) Preferred practice pattern: Amblyopia. American Academy of Ophthalmology, San Francisco.
[16] Nolan, A.F., McCann, A. and O’Keefe, M. (1997) Atropine penalisation versus occlusion as the primary treatment for amblyopia. British Journal of Ophthalmology, 81, 54-57. doi:10.1136/bjo.81.1.54

[17] Repka, M.X. and Ray, J.M. (1993) The efficacy of optical and pharmacological penalisation. Ophthalmology, 100, 769-775.

[18] Pediatric Eye Disease Investigator Group (2006) Treatment of anisometropic amblyopia in children with refractive correction. Ophthalmology, 113, 895-903. doi:10.1016/j.ophtha.2006.01.068

[19] Pediatric Eye Disease Investigator Group (2005) Twoyear follow-up of a 6-month randomized trial of atropine vs patching for treatment of moderate amblyopia in children. Archives of Ophthalmology, 123, 149-57. doi:10.1001/archopht.123.2.149

[20] Rahi, J.S., Cumberland, P.M. and Peckham, C.S. (2006) Does amblyopia affect educational, health and social outcomes? Findings from 1958 British birth cohort. British Journal of Haematology, 332, 820-825.

[21] Webber, A.L., Wood, J.M., Gole, G.A. and Brown, B. (2008) The effect of amblyopia on fine motor skills in children. Investigative Ophthalmology and Visual Science, 49, 594-603. doi:10.1167/iovs.07-0869

[22] Ip, J.M., Huynh, S.C., Kifley, A., et al. (2007) Variation of the contribution from axial length and other oculometric parameters to refraction by age and ethnicity. Investigative Ophthalmology and Visual Science, 48, 4846-4853. doi:10.1167/iovs.07-0101

[23] Holmes, J.M., Beck, R.W. and Repka, M.X. (2001) The Pediatric Eye Disease Investigator Group. The amblyopia treatment study visual acuity testing protocol. Archives of Ophthalmology, 119, 1345-1353.

[24] Birch, E.E., Williams, C., Hunter, J., Lapa, M.C. and ALSPAC (1997) Random dot stereoacuity of preschool children. Journal of Pediatric Ophthalmology \& Strabismus, 34, 217-222.

[25] Williams, C., Northstone, K., Harvey, I., Harrad, R. A. and Sparrow, J.M. (2002) Amblyopia treatment outcomes after screening before or at age 3 years: Follow up from randomised trial. British Medical Journal, 324, 15491551. doi:10.1136/bmj.324.7353.1549

[26] John, W., Simon, M.D. and Pamelakaw, M.D. (15 August 2001) Commonly missed diagnoses in the childhood eye examination. American Family Physician.

[27] Rahi, J.S., Logan, S., Timms, C., Russell-Eggitt, I., Taylor, D.S.I. (2002) Risk, causes, and outcomes of visual impairment after loss of vision in the non-amblyopic eye: A population-based study. Lancet, 360, 597-602. doi:10.1016/S0140-6736(02)09782-9

[28] Webber, A.L., Wood, J.M., Gole, G.A. and Brown, B. (2008) The effect of amblyopia on fine motor skills in children. Investigative Ophthalmology \& Visual Science, 49, 594-603. doi:10.1167/iovs.07-0869

[29] Grant, S., Melmoth, D.R., Morgan, M.J. and Finlay, A.L. (2007) Prehension deficits in amblyopia. Investigative Ophthalmology \& Visual Science, 48, 1139-1148. doi:10.1167/iovs.06-0976 
[30] Mazyn, L.I., Lenoir, M., Montagne, G., Delaey, C. and Savelsbergh, G.J. (2007) Stereo vision enhances the learning of a catching skill. Experimental Brain Research, 179, 723-726. doi:10.1007/s00221-007-0957-5

[31] Stifter, E., Burggasser, G., Hirmann, E., Thaler, A. and Radner, W. (2005) Monocular and binocular reading performance in children with microstrabismic amblyopia. British Journal of Ophthalmology, 89, 1324-1329. doi:10.1136/bjo.2005.066688

[32] Woodruff, G., Hiscox, F., Thompson, J.R. and Smith, L.K. (1994) The presentation of children with amblyopia. Eye,
8, 623-626. doi:10.1038/eye.1994.156

[33] Chua, B. and Mitchell, P. (2004) Consequences of amblyopia on education, occupation, and long term vision loss. British Journal of Ophthalmology, 88, 1119-1121. doi:10.1136/bjo.2004.041863

[34] Snowdon, S. and Stewart-Brown, S. (1997) Amblyopia and disability: A qualitative study. Health Services Research Unit, University of Oxford, Oxford.

[35] Rahi, J. and Cable, N. (2003) Severe visual impairment and blindness in children in the UK. Lancet, 362, 1359-1365. doi:10.1016/S0140-6736(03)14631-4 